\title{
The Exergy of Lift and Aircraft Exergy Flow Diagrams
}

\author{
David M. Paulus, Jr. \\ Research Associate \\ Technical University of Berlin \\ Institute for Energy Engineering \\ Marchstr. 18 Sek. KT1 \\ 10587 Berlin, Germany \\ d.paulus@iet.tu-berlin.de \\ Richard A. Gaggioli \\ Research Professor \\ Marquette University \\ 53233 Milwaukee, WI, USA
}

\begin{abstract}
Aside from incidental, auxiliary loads, in level flight the principal load on the aircraft propulsion engine is the power required to provide the continuous lift. To construct an exergy flow diagram for an aircraft - for example, for the purpose of pinpointing inefficiencies and for costing - an expression is needed for the exergy delivered to and by the wings. That is, an expression is needed for the exergy of lift. The purpose of this paper is to present an expression developed for the exergy of lift, applicable not only in level flight but in other modes of flight as well. In order to illustrate the relevance of exergy of lift, two exergy flow diagrams are presented for a light aircraft, one for level flight, and one for climb.
\end{abstract}

Key words: Exergy, second-law analysis, aircraft energy systems

\section{Introduction}

It is desirable to have a common commodity for multidisciplinary optimization of an aircraft, that allows charging the various systems for their use of resources. One common term proposed has been vehicle weight. Roth and Mavris (2000a) have developed methods for charging fuel weight (in addition to empty weight) to various aircraft systems. Additionally, Roth (2001) has developed methods for drag chargeability to various components.

The concept of exergy, a special case of Gibbs' available energy (Gaggioli et al., 2002) is a valuable tool for both the efficiency analysis, and the optimization of energy conversion systems. Recently there has been growing interest in applying exergy analysis, including "thermoeconomics", and other second-law methodologies, such as entropy generation minimization, to aircraft energy systems (e.g., Bejan (1999), Riggins (1996), Roth and Mavris (2000b) and others $\left.{ }^{1}\right)$. Moreover, the work on fuel chargeability mentioned above is essentially tracking exergy use by components, in that fuel is the source of exergy for an aircraft.

Aircraft energy systems are unique, in that exergy is required not only to operate them but also to lift them and to hold them aloft. In order to complete an exergy analysis, or apply thermoeconomics to an aircraft, it is necessary to create exergy flow diagrams. If such diagrams are successfully created, exergy ${ }^{2}$ becomes useable as a link between various aircraft systems during design. Required for this task is an expression for the exergy of lift.

\footnotetext{
${ }^{1}$ For a general overview of second-law methodologies, see Bejan et al. (1996). El-Sayed and Evans (1970) demonstrate the application of thermoeconomics to system decompositions. Additionally, the AIAA has published a special J. of Aircraft Issue on this subject (Vol. 40, Numb. 1, Jan.-Feb. 2003)

${ }^{2}$ or the specific costs of the exergy. These costs could be monetary, or could reflect other design goals, such as range or speed.
}

Int.J. Thermodynamics, Vol.6 (No.4) 
The exergy associated with the application of a force is been given by

$$
\dot{\mathrm{E}}=\mathrm{F}\left(\mathrm{V}-\mathrm{V}_{0}\right)
$$

Traditionally, for ordinary terrestrial applications, the "dead state" velocity $\mathrm{V}_{0}$ is set equal to zero - an earth-fixed reference frame is used. However, for aircraft, this assumption leads to the conclusion that the exergy needed to achieve and maintain lift is zero. Such a conclusion does not charge an on-board energy system for the exergy that must be supplied to "keep it aloft". The earth-fixed reference frame must be removed, and a proper reference with a vertical velocity component must be found.

Finding a proper $\mathrm{V}_{\mathrm{y} 0}$, or dead state velocity in the vertical direction, allows a proper calculation of the exergy of lift using the $y$ component of equation (1).

$$
\dot{\mathrm{E}}^{\mathrm{LI}}=\mathrm{F}_{\text {lift }}\left(\mathrm{V}_{\mathrm{y}}-\mathrm{V}_{\mathrm{y} 0}\right)
$$

Equation (2) is applicable to an aircraft as a whole when $F_{\text {lift }}$ is interpreted to be the vertical component of the total lift force upon the wing. Moreover, it is applicable to each subsystem of an aircraft, when $\mathrm{F}_{\text {lift }}$ is interpreted to be the vertical component of force delivered to the subsystem from the wing, via the aircraft's structure.

\section{Finding the "Dead State" Velocity}

McCormick (1995) state that the minimum induced drag coefficient of a wing is

$$
\mathrm{C}_{\mathrm{Di}, \min }=\frac{\mathrm{C}_{\mathrm{L}}^{2}}{\pi \mathrm{a}}
$$

where $\mathrm{a}$ is the aspect ratio. This minimum induced drag is for a wing with an elliptical shape; all departures from this shape will increase induced drag. For drag to be the minimum while producing a given amount of lift, no parasitic drag may be present, and the induced drag coefficient must be given by (3). This minimum drag force, $C_{D i, \text { min }} \rho S V_{\infty}^{2} / 2$, for a given lift is then given by

$$
\mathrm{F}_{\mathrm{drag}, \min }=\frac{\rho \mathrm{S} \mathrm{V}_{\infty}{ }^{2} \mathrm{C}_{\mathrm{L}}^{2}}{2 \pi \mathrm{a}}
$$

The minimum exergy input to the wing, again assuming a horizontal dead state velocity of zero and steady flight, is therefore

$$
\dot{\mathrm{E}}_{\min }^{\mathrm{TH}}=\frac{\rho \mathrm{S} \mathrm{V}_{\infty}{ }^{3} \mathrm{C}_{\mathrm{L}}^{2}}{2 \pi \mathrm{a}}
$$

An exergy balance on this wing in level flight results in

$$
0=\frac{\mathrm{dE}}{\mathrm{dt}}=\dot{\mathrm{E}}^{\mathrm{TH}}-\dot{\mathrm{E}}^{\mathrm{LI}}-\dot{\mathrm{E}}_{\delta}
$$

Presuming for now (and to be elaborated upon later) that flight with minimum drag is ideal (i.e., without exergy destruction), $\dot{\mathrm{E}}_{\delta}=0$. That is, in level flight all of the exergy input via thrust goes into lift: $\dot{\mathrm{E}}^{\mathrm{LI}}=\dot{\mathrm{E}}^{\mathrm{TH}}$. Then, substituting (2) for $\dot{\mathrm{E}}^{\mathrm{LI}}$ and (5) for $\dot{\mathrm{E}}^{\mathrm{TH}}$ yields the following expression for level flight,

$$
\mathrm{F}_{\text {lift }}\left(\mathrm{V}_{\mathrm{y}}-\mathrm{V}_{\mathrm{y} 0}\right)=\frac{\rho \mathrm{S} \mathrm{V}_{\infty}^{3} \mathrm{C}_{\mathrm{L}}^{2}}{2 \pi \mathrm{a}}
$$

Then, for level, unaccelerated flight with $\mathrm{V}_{\mathrm{y}}=0$ and $\mathrm{F}_{\text {lift }}=\mathrm{m}_{\mathrm{a}} \mathrm{g}$, it follows that

$$
-\mathrm{m}_{\mathrm{a}} \mathrm{g} \mathrm{V}_{\mathrm{y}, 0}=\frac{\rho \mathrm{S} \mathrm{V}_{\infty}{ }^{3} \mathrm{C}_{\mathrm{L}}^{2}}{2 \pi \mathrm{a}}
$$

The dead state velocity is then found to be equal

$$
\mathrm{V}_{\mathrm{y}, 0}=-\frac{\rho \mathrm{S} \mathrm{V}_{\infty}^{3} \mathrm{C}_{\mathrm{L}}^{2}}{2 \pi \mathrm{am} \mathrm{g}}
$$

Since $\mathrm{F}_{\text {lift }}^{2}=\left(\rho \mathrm{S} \mathrm{V}_{\infty}^{2} \mathrm{C}_{\mathrm{L}} / 2\right)^{2}$ and $\mathrm{F}_{\text {lift }}=\mathrm{m}_{\mathrm{a}} \mathrm{g}$, it follows that

$$
\mathrm{V}_{\mathrm{y}, 0}=-\frac{2 \mathrm{~m}_{\mathrm{a}} \mathrm{g}}{\pi \mathrm{a} \rho \mathrm{S} \mathrm{V}}
$$

With equations (2) and (10), the expression for the steady state exergy of lift for any component of mass $m_{c}$ is

$$
\dot{\mathrm{E}}_{\mathrm{c}}^{\mathrm{LI}}=\mathrm{m}_{\mathrm{c}} \mathrm{g}\left(\mathrm{V}_{\mathrm{y}}+\frac{2 \mathrm{~m}_{\mathrm{a}} \mathrm{g}}{\pi \mathrm{a} \rho \mathrm{S} \mathrm{V}}\right)
$$

or, in terms of wing loading and free-stream dynamic pressure

$$
\dot{\mathrm{E}}_{\mathrm{c}}^{\mathrm{LI}}=\mathrm{m}_{\mathrm{c}} \mathrm{g}\left(\mathrm{V}_{\mathrm{y}}+\frac{\mathrm{V}_{\infty}(\mathrm{W} / \mathrm{S})}{\pi \mathrm{a} \mathrm{q_{ \infty }}}\right)
$$

\section{Elaboration on the Dead State Velocity}

The rate of climb in a light aircraft, when the flight path angle $\gamma$ is not steep, is well approximated (McCormick, 1995) with 


$$
\mathrm{V}_{\mathrm{y}}=\frac{\dot{\mathrm{W}}-\dot{\mathrm{W}}_{\mathrm{req}}}{\mathrm{mg}}
$$

where $\dot{\mathrm{W}}$ is the power supplied, and $\dot{\mathrm{W}}_{\text {req }}$ is the power required for level flight. The difference is commonly referred to as "excess power".

If the power supplied is zero, and the aircraft is ideal ${ }^{3}$,

$$
\mathrm{V}_{\mathrm{y}}=-\frac{\rho \mathrm{S} \mathrm{V}{ }_{\infty}{ }^{3} \mathrm{C}_{\mathrm{L}}^{2}}{2 \pi \mathrm{amg}}
$$

This is noted to be the same as $\mathrm{V}_{\mathrm{y} 0}$ given by equation (9). Thus, at a given forward velocity $\mathrm{V} \infty$, the dead state velocity corresponds to the speed of descent of an ideal wing, at zero power input, that is to say, the speed of descent in a steady-state glide.

Additionally, the dead state velocity corresponds to the downwash velocity of a finite, elliptical wing. This is not surprising, as equation (3) is essentially developed by finding the downwash velocity.

\section{Creation of Exergy Flow Diagrams}

The relationship for the exergy of lift will presently be applied to a light aircraft, the Glastar $^{\mathrm{TM}}$ homebuilt aircraft, developed by Arlington Aircraft Development, Inc. The aircraft has a gross weight of $889 \mathrm{~kg}(1960 \mathrm{lb}$.). The Glastar uses a NASA GAW-2 airfoil, has a wingspan of $10.7 \mathrm{~m}$ (35 feet), and an aspect ration of 9.6. For the purpose of this article, the aircraft will be assumed to be powered by a 119 $\mathrm{kW}$ (160 hp) O-320 engine with a constant-speed Hartzell propeller and to have an empty weight of $544 \mathrm{~kg}(1200 \mathrm{lb}$.). The exergy flow diagrams are for a gross weight of $834.6 \mathrm{~kg}(1840 \mathrm{lb}$.), carrying $54.43 \mathrm{~kg}(120.0 \mathrm{lb}$.) of fuel.

Two exergy flow diagrams will be presented, one for full-throttle cruise $(75 \%$ power) at an altitude of $2440 \mathrm{~m}$ (8000 feet) and one for maximum rate of climb at sea level.

The aircraft was divided into the following components: Fuel, engine, propeller, wing, fuselage and empennage (the horizontal and vertical stabilizers), and cargo. Masses of these components are given in TABLE I. Trim and non-wing parasitic drag were attributed to the fuselage and empennage component.

\footnotetext{
${ }^{3}$ Here, imagine an aircraft with elliptical wings, producing no parasitic or trim drag.
}

TABLE I. MASSES OF AIRCRAFT COMPONENTS

Component Mass $(\mathrm{kg})$

\begin{tabular}{cc}
\hline Fuel & 54.43 \\
\hline Engine & 123.8 \\
\hline Propeller & 18.14 \\
\hline Wing & 181.4 \\
\hline $\begin{array}{c}\text { Fuselage and } \\
\text { Empennage } \\
\text { Cargo }\end{array}$ & 235.9 \\
\hline & 220.9
\end{tabular}

\subsection{The Aircraft Flight Model}

The aircraft performance model employed to create the exergy flow diagrams is vastly simplified. The wing induced drag was assumed to follow the equation (McCormick, 1995)

$$
\mathrm{C}_{\mathrm{Di}}=\mathrm{C}_{\mathrm{Di}, \min }+\frac{\mathrm{C}_{\mathrm{L}}^{2}}{\pi \mathrm{a} \mathrm{e}}
$$

where $e$, Oswald's efficiency factor is given by

$$
\mathrm{e}=\frac{1}{1+\delta+\mathrm{k} \pi \mathrm{a}}
$$

The value $\delta$ was set to 0.17 based on McCormick Figure 4.21. The value $\mathrm{k}$ was found from a best fit to published $C_{d}$ versus $C_{1}$ data (McGhee et al., 1977). A figure of 0.009 was added to the results of equation (15) as an estimate of the parasitic drag of the wing.

The parasitic drag of the remainder of the aircraft and the trim drag were lumped together and calculated via

$$
\mathrm{F}_{\text {drag, fuse }}=\frac{1}{2} \rho \mathrm{A}_{\text {equiv }} \mathrm{V}_{\infty}{ }^{2}
$$

The equivalent area was estimated to be $0.1911 \mathrm{~m}^{2}\left(2.057 \mathrm{ft}^{2}\right)$ by tuning the model to best approximate published aircraft performance.

Although the performance model is perfectly adequate for the purpose of this paper, it tends to slightly underestimate the aircraft's climb performance. Some of this underestimation is likely due to the use of equation (13) to calculate climb rate, as the Glastar has a very steep maximum performance climb for a light propeller-driven aircraft.

\subsection{Exergy Balances}

The exergy flow diagrams were created by applying the following exergy balances. Note that in the equations below, the term $\dot{\mathrm{E}}_{\text {wing }}^{\mathrm{TH}}$ 
includes not only the thrust supplied to overcome drag, but also the excess power, as used in equation (13).

Fuel:

$$
\begin{aligned}
\frac{\mathrm{dE}_{\text {fuel }}}{\mathrm{dt}}= & \mathrm{m}_{\text {fuel }} \mathrm{g} \frac{\mathrm{dY}}{\mathrm{dt}}-\dot{\mathrm{m}}_{\text {fuel }} \mathrm{e}_{\text {fuel }}^{\mathrm{CH}}= \\
& \dot{\mathrm{E}}_{\text {fuel }}^{\mathrm{LI}}-\dot{\mathrm{m}}_{\text {fuel }} \mathrm{e}_{\text {fuel }}^{\mathrm{CH}}-\dot{\mathrm{E}}_{\delta, \text { fuel }}
\end{aligned}
$$

Engine:

$$
\begin{aligned}
& \frac{\mathrm{dE}_{\text {engine }}}{\mathrm{dt}}=\mathrm{m}_{\text {engine }} \mathrm{g} \frac{\mathrm{dY}}{\mathrm{dt}}= \\
& \dot{\mathrm{m}}_{\text {fuel }} \mathrm{e}_{\text {fuel }}^{\mathrm{CH}}+\dot{\mathrm{E}}_{\text {engine }}^{\mathrm{LI}}-\dot{\mathrm{W}}_{\text {prop }}-\dot{\mathrm{E}}_{\delta \text {, engine }}
\end{aligned}
$$

Propeller:

$$
\begin{aligned}
\frac{\mathrm{dE}_{\text {prop }}}{\mathrm{dt}}= & \mathrm{m}_{\text {prop }} \mathrm{g} \frac{\mathrm{dY}}{\mathrm{dt}}= \\
& \dot{\mathrm{E}}_{\text {prop }}^{\mathrm{LI}}+\dot{\mathrm{W}}_{\text {prop }}-\dot{\mathrm{E}}_{\text {prop }}^{\mathrm{TH}}-\dot{\mathrm{E}}_{\delta \text {, prop }}
\end{aligned}
$$

Wing:

$$
\begin{aligned}
\frac{d E_{\text {wing }}}{d t}= & m_{\text {wing }} g \frac{d Y}{d t}= \\
& \dot{E}_{\text {wing }}^{\mathrm{TH}}-\dot{\mathrm{E}}_{\text {lift,net }}^{\mathrm{LI}}-\dot{\mathrm{E}}_{\delta \text {,wing }}
\end{aligned}
$$

Fuselage and Miscellaneous:

$$
\begin{aligned}
\frac{\mathrm{dE}_{\text {fuse }}}{\mathrm{dt}}= & \mathrm{m}_{\text {fuse }} \mathrm{g} \frac{\mathrm{dY}}{\mathrm{dt}}= \\
& \dot{\mathrm{E}}_{\text {fuse }}^{\mathrm{LI}}+\dot{\mathrm{E}}_{\text {fuse }}^{\mathrm{TH}}-\dot{\mathrm{E}}_{\delta \text {,fuse }}
\end{aligned}
$$

Cargo:

$$
\begin{aligned}
\frac{\mathrm{dE}_{\text {cargo }}}{\mathrm{dt}}= & \mathrm{m}_{\text {cargo }} \mathrm{g} \frac{\mathrm{dY}}{\mathrm{dt}}= \\
& \dot{\mathrm{E}}_{\text {cargo }}^{\mathrm{LI}}-\dot{\mathrm{E}}_{\delta \text {, cargo }}
\end{aligned}
$$

\subsection{Other Relations}

For an aircraft in steady flight, the total lift must be equal to the total weight of the aircraft. From equation (11) it can be seen that the lift generated by the wing will be consumed by individual components of an aircraft proportionally to their weight. ${ }^{4}$ For example, for the engine

\footnotetext{
${ }^{4}$ Roth (2001) charges induced drag proportional to weight,

${ }^{4}$ Roth (2001) charges induced drag proportional to weight,
and makes the argument that the zero-lift drag of the wing could also be so charged. Inasmuch that the wing drag is the exergetic fuel for the lift exergy, the division of lift exergy, in this paper, and wing drag, by Roth, are done in a consistent manner.
}

$$
\dot{\mathrm{E}}_{\text {engine }}^{\mathrm{LI}}=\frac{\mathrm{m}_{\text {engine }} \mathrm{g}}{\mathrm{m}_{\mathrm{a}} \mathrm{g}} \dot{\mathrm{E}}^{\mathrm{LI}}
$$

Likewise, the net exergy of lift delivered by the wing was defined as

$$
\dot{\mathrm{E}}_{\text {net }}^{\mathrm{LI}}=\dot{\mathrm{E}}^{\mathrm{LI}}-\frac{\mathrm{m}_{\text {wing }} \mathrm{g}}{\mathrm{m}_{\mathrm{a}} \mathrm{g}} \dot{\mathrm{E}}^{\mathrm{LI}}
$$

Thrust exergy flow from the propeller was found with the following equation.

$$
\dot{\mathrm{E}}_{\text {prop }}^{\mathrm{TH}}=\eta_{\text {prop }} \dot{\mathrm{W}}_{\text {prop }}
$$

Engine performance was taken from the Lycoming operator's handbook, and propeller efficiency was found via Hartzell's performance software. Fuel flows at cruise and maximum climb are 0.006350 and $0.01210 \mathrm{~kg} / \mathrm{s}$, respectively. The specific chemical exergy of the fuel was assumed to be $46000 \mathrm{~kJ} / \mathrm{kg}$.

\section{Example Exergy Flow Diagrams}

The general flow of exergy in the aircraft is shown in Figure 1. The values of the flows, as well as rates of change in exergy content, and exergy destruction are given in TABLE I and TABLE III, for cruise flight and climb, respectively.

To track the exergy flows on the diagrams, note first that the fuel is the source of exergy for the aircraft. (Also, observe that the fuel itself requires a lift exergy input so as to be held aloft.) The fuel's exergy is supplied, naturally to the engine, which converts it to mechanical power. The engine's mechanical power is used to drive the propeller (and also auxiliaries, such as an alternator and vacuum pump, not included in this analysis). The propeller creates thrust exergy, supplied to the wing to produce lift and to overcome the drag of the remainder of the aircraft.

The wing's exergy of lift is supplied to itself and all other components of the airplane. Thus, a portion of the fuel's exergy makes a full circle journey in being converted to lift to keep itself in the air.

At cruise flight, for each component the difference between inflows and outflows of exergy is the rate of exergy destruction, as the diagrams are at steady state. Only the fuel shows a time rate of change, as the finite supply is being expended. For climbing flight, there is a rate of change in all of the component's exergy due to the increase in altitude. 


\section{Discussion}

Examination of the exergy flow diagram leads to the question, "What happens to this lift exergy supplied to various aircraft components?" It is, of course, ultimately destroyed in the process of holding the system out of equilibrium with the environment. This is much the same as in other processes, such as heating a house. To keep a house at a higher (or lower) temperature than its environment, one must continuously supply heat exergy. This exergy is continuously "used up". The exergy content of the house at any instant is the maximum amount of energy that could be obtained by bringing the house to equilibrium with its surrounding environment (that is, the available energy of the composite of house and its surrounding environment;(Gibbs, 1961 and Gaggioli et al., 2002). The appropriate "dead state temperature" for evaluation of the house exergy content is the temperature that would be reached by such an equilibration process.

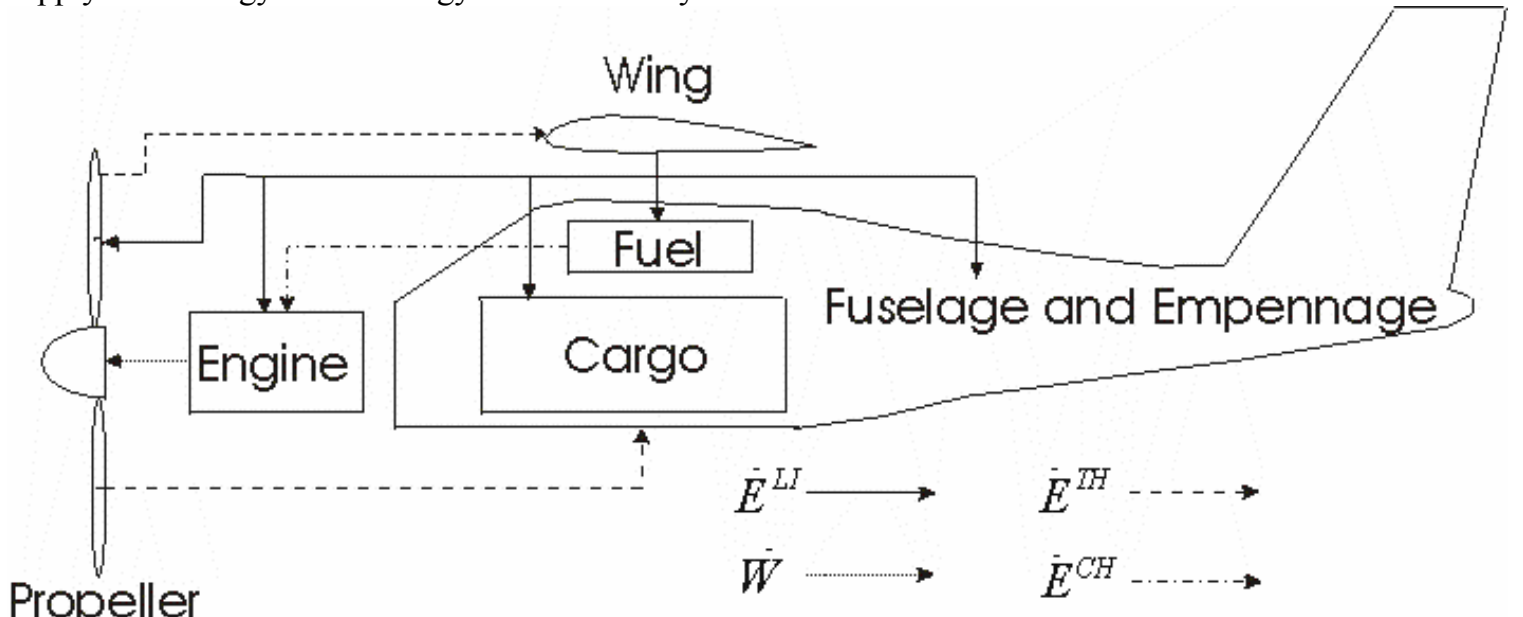

Figure 1. General Aircraft Exergy Flows (TABLE II and TABLE III for numerical values.)

TABLE II. AIRCRAFT EXERGY FLOWS, RATES OF CHANGE AND DESTRUCTION, CRUISE FLIGHT, $\mathrm{V}_{\infty}=72.14 \mathrm{~m} / \mathrm{s}(161.4 \mathrm{MPH})(\mathrm{kW},-$ INDICATES OUTFLOW $)$

\begin{tabular}{ccccccc}
\hline Component & $\dot{\mathrm{E}}^{\mathrm{LI}}$ & $\dot{\mathrm{E}}^{\mathrm{TH}}$ & $\dot{\mathrm{W}}$ & $\dot{\mathrm{E}}^{\mathrm{CH}}$ & $\dot{\mathrm{E}}_{\delta}$ & $\mathrm{dE} / \mathrm{dt}$ \\
\hline Fuel & 0.3681 & & & -292.1 & 0.3681 & -292.1 \\
\hline Engine & 0.8374 & & -89.48 & 292.1 & 203.5 & 0 \\
\hline Propeller & 0.1227 & -72.84 & 89.48 & & 16.77 & 0 \\
\hline Wing & -4.417 & 39.97 & & 35.56 & 0 \\
\hline Fuselage and Empennage & 1.595 & 32.87 & & 34.46 & 0 \\
\hline Cargo & 1.494 & & & 1.494 & 0 \\
\hline
\end{tabular}

TABLE III. AIRCRAFT EXERGY FLOWS, RATES OF CHANGE AND DESTRUCTION, MAXIMUM CLIMB, $6.813 \mathrm{~m} / \mathrm{s}(1341 \mathrm{FT} / \mathrm{MIN}), \mathrm{V}_{\infty}=40.63 \mathrm{~m} / \mathrm{s}(90.88 \mathrm{MPH})(\mathrm{kW},-$ INDICATES OUTFLOW)

\begin{tabular}{ccccccc}
\hline Component & $\dot{\mathrm{E}}^{\mathrm{LI}}$ & $\dot{\mathrm{E}}^{\mathrm{TH}}$ & $\dot{\mathrm{W}}$ & $\dot{\mathrm{E}}^{\mathrm{CH}}$ & $\dot{\mathrm{E}}_{\delta}$ & $\mathrm{dE} / \mathrm{dt}$ \\
\hline Fuel & 4.124 & & & -556.4 & 0.4902 & -552.8 \\
\hline Engine & 9.383 & & -119.3 & 556.4 & 438.2 & 8.283 \\
\hline Propeller & 1.375 & -81.00 & 119.3 & & 38.47 & 1.205 \\
\hline Wing & -49.49 & 73.17 & & 11.57 & 13.32 \\
\hline Fuselage and Empennage & 17.87 & 7.828 & & & 9.952 & 15.75 \\
\hline Cargo & 16.74 & & & 1.989 & 14.75 \\
\hline
\end{tabular}


Likewise, the exergy content of an aircraft is the maximum amount of energy that could be obtained by bringing the aircraft to equilibrium with its environment. At the resultant "dead" state - with the aircraft at equilibrium with its environment - the vertical component of velocity would be $\mathrm{V}_{\mathrm{y} 0}$, in accord with Equation (8). That is, at the dead state, the plane would be gliding, descending at the speed corresponding to $\mathrm{V}_{\mathrm{y} 0}$, as shown by Equation (11). (During an actual glide, kinetic exergy of the aircraft - associated with its horizontal component of velocity - is being dissipated by viscous drag.)

Another expression arising from the expression for lift exergy presented here is its dependence on aspect ratio. Namely, as the aspect ratio becomes very large, the exergy of lift becomes very small. This is consistent, as the theoretical minimal exergy input to these wings would also become negligible (and equal to the lift exergy delivered), and the output (lift exergy) must remain less than (for the real case) or equal to (for the ideal case) the output.

The expression presented in this paper is applicable to subsonic, steady flight outside of ground effect. The presence of shock waves in supersonic flight may require the expression to be reevaluated. In ground effect, the earth surface becomes an important part of the surroundings, and needs to be included in the determination of the dead-state vertical velocity. It could be argued that the inclusion of the surface of the earth as part of the surrounding would force a dead-state vertical velocity of zero, resulting in a zero exergy of lift while in ground effect - consistent with the vast reduction in drag of an aircraft due to the ground effect.

\section{Conclusions}

If it is desired to apply exergy analysis (including thermoeconomics) to aircraft, an expression for the exergy of lift is needed. This is because a significant amount of exergy is required to hold the each component of the aircraft aloft. A suitable expression has been derived here, and employed to develop exergy flow diagrams. These diagrams are valuable for quantitatively tracking exergy flows from the source (fuel) to the "users" (subsystems) and for pinpointing and assessing inefficiencies. Moreover, when combined with money balances, the exergy analysis and flow diagrams allow costs of "energy" and "energy conversion" to be tracked - that is, provide a means for rational cost accounting, associated with the exergy flows. These costs are key to thermoeconomic decomposition. (See Paulus and Gaggioli (2003) for an application to the aircraft of Figure 1.)

The diagram of Figure 1 is based upon a very simple breakdown of the aircraft. A more detailed aircraft performance model could further break down exergy flows in the "fuselage and miscellaneous" category.

\section{Acknowledgement}

This work was carried out under a contract with the Air Force Office of Scientific Research. Also, the authors would like to thank the reviewers, who gave many comments that were helpful for improving the paper.

\section{Nomenclature}

$\begin{array}{ll}a & \text { Aspect ratio } \\ \mathrm{C}_{\mathrm{d}} & \text { Coefficient of drag for an infinite span } \\ \mathrm{C}_{\mathrm{D}} & \text { Coefficient of drag for a finite span } \\ \mathrm{C}_{1} & \text { Coefficient of lift for an infinite span } \\ \mathrm{C}_{\mathrm{L}} & \text { Coefficient of lift for a finite span } \\ \mathrm{e} & \text { Oswald's efficiency factor } \\ \mathrm{E} & \text { Exergy } \\ \mathrm{e} & \text { Specific exergy } \\ \mathrm{F} & \text { Force } \\ \mathrm{g} & \text { Acceleration of gravity } \\ \mathrm{k} & \text { Constant for Oswald's efficiency factor } \\ \mathrm{q} & \text { Dynamic pressure } \\ \mathrm{S} & \text { Wing surface area } \\ \mathrm{V} & \text { Velocity } \\ \dot{\mathrm{W}} & \text { Power } \\ \mathrm{W} / \mathrm{S} & \text { Wing loading } \\ \mathrm{Y} & \text { Altitude }\end{array}$

Greek Symbols

$\begin{array}{ll}\delta & \text { Constant for Oswald's efficiency factor } \\ \eta & \text { Efficiency } \\ \rho & \text { density }\end{array}$

$\begin{array}{ll}\text { Subscripts } & \\ 0 & \text { Dead state } \\ \infty & \text { Free stream } \\ \mathrm{a} & \text { aircraft } \\ \mathrm{c} & \text { component } \\ \mathrm{i} & \text { Induced } \\ \text { min } & \text { Minimum } \\ \mathrm{y} & \text { y-component } \\ \delta & \text { Destruction }\end{array}$

$\begin{array}{ll}\text { Superscripts } & \\ \text { CH } & \text { Chemical exergy } \\ \text { LI } & \text { Lift exergy } \\ \text { TH } & \text { Thrust exergy }\end{array}$




\section{References}

Bejan, A., 1999, "Role for exergy analysis and optimization in aircraft energy-system design", American Society of Mechanical Engineers, Advanced Energy Systems Division (Publication) Aes. Vol.39, pp. 209-217.

Bejan, A., Tsatsaronis, G. and Moran, M. J., 1996, Thermal Design and Optimization, John Wiley and Sons, NY.

El-Sayed, Y.M. and Evans, R.B., 1970, ASME Journal of Engineering for Power, Vol.92, p.27.

Gaggioli, R. A., 1998, Int. J. Applied Thermodynamics, Vol.1, pp. 1-8

Gaggioli, R.A., Richardson, D.H., Bowman, A. J. and Paulus, D. M. Jr., 2002, Available Energy - Part I: Gibbs Revisited, Part II: Gibbs Extended, Trans. ASME, J. of Energy Resources Technology, vol. 124, pp. 105-115.

Gibbs, J.W., 1961, “A Method of Geometrical Representation of the Thermodynamic Properties of Substances, and Graphical Methods in the Thermodynamics of Fluids", The Scientific Papers of J.W. Gibbs, Vol.1

McCormick, B. W., 1995, Aerodynamics, Aeronautics and Flight Mechanics, John Wiley and Sons, New York, NY.

McGhee, R. J., Beasley, W. D. and Somers, D. M., 1977, "Low-Speed Characteristics of a 13Percent-Thick Airfoil Section Designed for General Aviation Applications", NASA Technical Memorandum TM X-72697.

Paulus, D. M. Jr. and Gaggioli, R. A., 2001, "The Exergy of Lift, and Aircraft Exergy Flow Diagrams", ASME AES-Vol.41, ASME, New York.

Paulus, D. M. Jr. and Gaggioli, R. A., 2003, "Rational Objective Functions for Vehicles", AIAA J. of Aircraft, Vol.40, No.1, pp. 27-34.

Riggins, D. W., 1996, "Brayton Cycle Engine/Component Performance Assessment Using Energy and Thrust-Based Methods", AIAA Paper 1996-2922.

Roth, B. A. and Mavris, D. N., 2000a, "Technology Evaluation via Loss Management Models formulated in Terms of Vehicle Weight", SAWE Paper 3001, 59 $9^{\text {th }}$ Annual Conference of the Society of Allied Weight Engineers, St. Louis.

Roth, B. A. and Mavris, D. N., 2000b, "A Generalized Model for Vehicle Thermodynamic Loss Management and Technology Concept Evaluation”, SAE Paper 2000-015562, 2000 World Aviation Conference, Sand Diego.
Roth, B. A., 2001, “Aerodynamic Drag Loss Chargeability and its Implication in the Vehicle Design Process", AIAA Paper 20015236, AIAA Aircraft, Technology Integration and Operations Forum, Los Angeles.

\section{Appendix}

\section{Available Energy}

The development presented here for the exergy of lift was motivated by contemplation of "useful energy" transfers in aircraft within Gibbs original presentation of the concept of "available energy" (Gaggioli et al, 2002). Gibbs first presented the concept for an arbitrary overall system and then, as a special case, for the situation when the overall system includes a "medium" - a very large subsystem, which, by itself, is at equilibrium. In any case, at any state of the overall system, the available energy is equal to the energy at that state minus the minimum value of energy at states that could be reached without net transfer of any of the additive properties designated (arbitrarily) as the "constraints" - i.e., any of the additive properties whereby energy transfers to or from the overall systems and exchanges between subsystems are allowed.

In Volume 1 of this journal, Gaggioli (1998) has shown that in the general case, with or without a medium, it is possible to define an exergy for each subsystem, to represent that subsystem's contribution to the overall system's available energy. (Also see Gaggioli et al, 2002.)

For the present case, aircraft in the earth's atmosphere, we have taken the overall system to be the aircraft and its contents, the air surrounding the aircraft and the earth's gravitational field. Moreover, we took the constraints to be, practically, entropy, volume, $\mathrm{x}$-momentum of the aircraft and earth (i.e., in the horizontal direction of flight) and the $y$ momentum of the aircraft and earth (in the vertical direction). Thus, it is assumed that, practically, energy associated with the $\mathrm{x}$ - or $\mathrm{y}$ momentum of the air is not transferable to or from the overall system (and hence is not "available"). Therefore, for example, the energy associated with the "downwash" velocity of the air leaving the aircraft wing is not available. This, we maintain, is analogous to the supposed unavailability of the kinetic energy of the molecules of a gas such as Xenon (or other molecule) that is at equilibrium in a rigid, insulated container.

It follows, then, that at any state of our overall system the corresponding state of minimum energy has the aircraft descending 
with a vertical speed equal to $\mathrm{V}_{\mathrm{y} 0}$ (which is also the downwash velocity in level flight). This state of minimum energy defines the "equilibrium state" of the overall system - the state the system would "come to" if its energy were reduced to a minimum by ideal processes with no net transfers of energy via the presumed constraints. That is, if the maximum conceivable amount of energy were removed from the overall system with no net transfer of the constraints.
Alternative Derivation of $V_{y 0}$

In the foregoing paper, the development leading to equation (14) could be taken as the derivation of an expression for $\mathrm{V}_{\mathrm{y} 0}$. And, in turn, the development of the expression equation (10) could be reversed to prove that the rate of exergy destruction is zero when an aircraft, with an elliptical wing that has no parasitic drag, is in straight and level flight. 